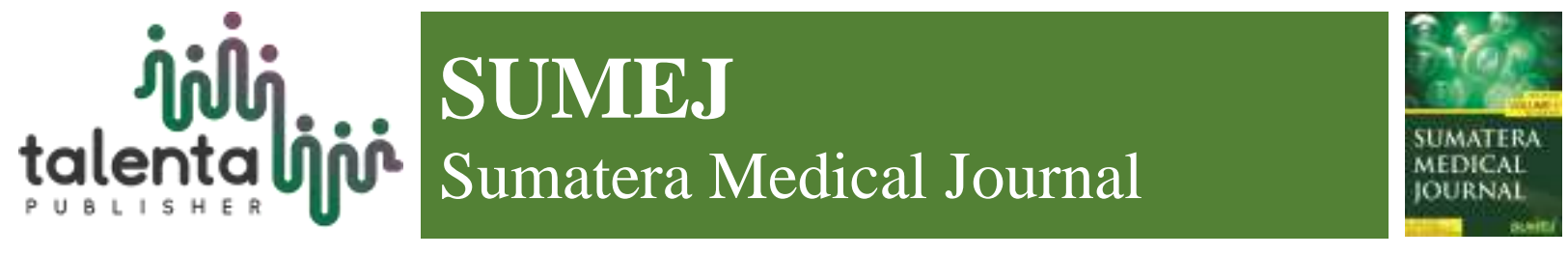

\title{
Equianalgesic Oxycodone, Continuous Intravenous Morphine in Post- Long Bone Surgery
}

\author{
F.J. Tarigan, A. Hanafie, H. Arifin, and D.W. Wijaya \\ Department of Anesthesiology and Intensive Therapy, Faculty of Medicine, Universitas Sumatera Utara
}

\begin{abstract}
Oxycodone and morphine are powerful analgesic drugs used for post-operative pain management, and no studies have been conducted to get an equianalgesic dose of Oxycodone and Morphine. This study was using a double-blind randomized clinical trials, 48 samples, ages 21-60 years, PS ASA I-II, which will get an elective orthopedic surgery using general anesthesia techniques. The drug is given when the patient has extubated. Oxycodone (group A) : Morphine (group B) (Initial 5mg than continuous 1 $\mathrm{mg} /$ hour : initial dose $4 \mathrm{mg}$ than continuous $0,5 \mathrm{mg} / \mathrm{hour}$ ). Average drug dose for group that takes morphine and oxycodone $(3.90 \pm 0.46 \mathrm{mg}: 1.46 \pm 0.51 \mathrm{mg})$. No significant difference between the average dose $(\mathrm{p}<0.05)$. Equianalgesic doses in group Oxycodone and Morphine is $1.4 \mathrm{mg}: 3.9 \mathrm{mg}$.
\end{abstract}

Keyword: Oxycodone, Morphine, Visual Analogue Score, Equianalgesic Dose

Received 23 Aug 2019.| Revised 22 Sep 2019| Accepted 30 Sep 2019

${ }^{*}$ Corresponding author at: Jl. Karya Sembada no.216, Medan, Indonesia

E-mail address: franzjoseftarigan@hotmail.com 


\section{Introduction}

Pain is a subjective feeling or experience that involves sensory, emotional and unpleasant behavior associated with tissue damage or potential damage to tissue. If pain is not addressed, it can have a negative impact on post-surgical patients such as anxiety (sleep disturbance) immunosuppression, hyperglycemia, hemodynamic changes (hypertension, tachycardia), decreased breathing movements, causing coughing, fears to move will increase the risk of thromboembolic complications and increase catecholamine release leading to increased vascular resistance, prolong catabolic phase, decrease blood flow to the inferior extremity and decreases the blood circulation to the splanchnic. The most commonly used opioid drug today is morphine because of its rapid spontaneous analgesia and also its duration of action. Opioid receptors are synthesized and increase in the number of sensory nerves to both central and peripheral, while endogenous opioids binding to these receptors cause decreased neural fibers' impaired stimulation.

Oxycodone is an agonist receptor of mu and kappa opioid, structurally similar to codeine, but pharmacodynamically similar to morphine. In addition to having analgesia effects, oxycodone also causes anxiolysis, euphoria, calm feeling, and cough suppression, as well as respiratory depression, constipation, miosis, sweating, and drowsiness. will eventually in-crease the cost of treatment. (Morgan, 2013) (Rawal, 2008) (Stoelting, 2006)

Oxycodone in various preparations has a broad effect to be used as a therapeutic efficacy. Morphine is an opioid used to treat severe pain and is used as a reference to the work mechanism of other opioid drugs. Morphine should be used with caution against people with renal failure because of its active metabolites (morphine-6-glucoronide) that can cause respiratory failure, (Misiolek, 2014).

In 2010, Plante examined that intravenous administration of oxycodone required a 1.5 times greater dose than morphine. (Plante, 2010) Oxycodone is an alternative medicine for patients who experience side effects against other types of opioids, such as morphine (eg hallucinations), conversion factors for other opioids used only as a general guide. Always use a conservative approach when switching from one type of opioid to another, in other words, starting from a low dose. The estimated conversion ratio between intravenous oxycodone and intravenous morphine is 1 : 1 , ie $1 \mathrm{mg}$ intravenous oxycodone is equivalent to $1 \mathrm{mg}$ of intravenous morphine at a dose for each patient must be titrated individually to achieve the optimum dose for pain management. (Mundipharma, 2015)

In 1997 at Helsinki, a study was conducted evaluating postoperative pain management with PCA in 50 subjects undergoing spine surgery, found to use morphine $45 \mathrm{mcg} / \mathrm{kgBW}$ and oxycodone $30 \mathrm{mcg} / \mathrm{kgBW}$ had the same effectiveness in dealing with postoperative pain. (Silvasti, 1998) 
In 2009 a study of the management of postoperative pain in 91 female subjects undergoing laparoscopic hysterectomy surgery. It was found at the same dose of $0.015 \mathrm{mg} / \mathrm{kg}$ body weight which received oxycodone proved to have a lower VAS compared to morphine. (Lenz, 2009).

In theory, oxycodone is an analgesic alternative to morphine which can be used for postoperative pain relief with milder side effects. No studies have been conducted to determine the equivalence of doses on the analgesic effect of these two drugs. This research is the first to be done in Asians. From some of the studies above, it appears that the dosages used on these two drugs differ. This is what underlies the need for a study to find out the equivalence of these two analgesic doses, to facilitate the conversion of these two drugs.

\section{Methodology}

Design : The design of this study used randomized controlled and double-blinded clinical trials. To determine the equivalence of analgesic doses (equianalgesic doses) oxycodone with continuous infusion morphine in overcoming pain with VAS assessment after long bone surgery under general anesthesia.

\section{Time and Place :}

This research was conducted in Haji Adam Malik General Hospital in Medan, North Sumatera. The study began on $1^{\text {st }}$ of August 2017 until $25^{\text {th }}$ of September 2017, after the ethical clearance and permission from the Haji Adam Malik General Hospital were issued.

Population and Sample : The study sample was a population that fulfilled inclusion and exclusion criteria. This sample was di-vided into 2 groups:

- Group A receives intravenous continuous oxycodone infusion with target VAS value $\leq 3$.

- Group B receives intravenous continuous morphine infusion with target values of VAS $\leq 3$.

Then the patient is separated by inclusion and exclusion criteria.

\section{Inclusion Criteria:}

1. Aged 21-60 years old

2. Patients undergoing long bone surgery

3. Patients with ASA Physical Status 1 and 2

4. Patients agree to participate in the study 
Exclusion criteria: Patients who have opioid analgesics prior to surgery

Drop out criteria: Cardiovascular and pulmonary emergencies, allergic reaction observed after the use of the drugs.

Numbers of sample : From the calculation with the formula, then obtained a sample size of 20 people plus $20 \%$ if there is a test break up to 24 people. So the total sample of the two groups was 44 people.

\section{Preparation :}

After receiving an explanation of the procedure to be performed and signing an informed consent, all samples were measured for PBW (Predicted Body Weight), then the study subjects were included in the inclusion and exclusion criteria.

Samples were randomly divided into 2 groups, namely group A received continuous intravenous oxycodone infusion and group B received continuous intravenous morphine infusion, then randomized double-blind infusion by trained volunteers. Randomization is done by block, each sequence consisting of six subjects, with the number of possible combinations of sequences of eight. Then the pen is dropped on a random number. Then the sequences obtained are arranged sequentially according to the envelope number.

The drug is prepared by volunteers who carry out randomization (researchers do not know the composition of the drugs given). To make oxycodone preparations, oxycodone is taken as much as $50 \mathrm{mg}$. then dissolved with $0.9 \% \mathrm{NaCl}$ to $50 \mathrm{ml}$, so that each $1 \mathrm{ml}$ solution contains $1 \mathrm{mg}$ of oxycodone, connected to the three ways with an extension tube, given with a Syringe Pump, with initial administration of $5 \mathrm{mg}$ bolus and an increase in dose of $1 \mathrm{mg} /$ hour (1 $\mathrm{ml})$ until the target VAS value $\leq 3$ is reached. To make morphine preparations, morphine is taken as much as $25 \mathrm{mg}$ and then dissolved with $0.9 \% \mathrm{NaCl}$ solution to $50 \mathrm{ml}$ so that every $1 \mathrm{ml}$ solution contains $0.5 \mathrm{mg}$ of morphine, connected to three ways with an extension tube, given with a Syringe Pump, with an initial administration of $4 \mathrm{mg}$ and an increase in dose of $0.5 \mathrm{mg} /$ hour $(1 \mathrm{ml})$ until the target VAS value $\leq 3$ is reached.

During the process of increasing the syringe pump dose filled with medicine, it is closed with a paper. Only volunteers can take medicine to fill the medicine.

\section{Procedure :}

After the patient arrived in the waiting room of the operating room, the patient was rechecked for identity, diagnosis, anesthesia plan, access to infusion (make sure the infusion has been installed with $18 \mathrm{G}$ abocath, threeway and smooth infusion flow). 
Then the patient was brought to the operating room, then a standard monitor was installed (ECG, blood pressure, heart rate, breathing frequency, oxygen saturation).

Both groups of patients were given preloading liquid Ringer Lactate $10 \mathrm{ml} / \mathrm{kgBW}$ and were prepared for general anesthesia then premedication with fentanyl $2 \mathrm{mcg} / \mathrm{kg}$, midazolam $0.05 \mathrm{mg}$ / kg, wait 5 minutes onset. The patients were induced with propofol $2 \mathrm{mg} / \mathrm{kg}$, rocuronium $1 \mathrm{mg}$ $/ \mathrm{kg}$, after onset was reached for 1 minute, direct laryngoscopy was performed with a laryngoscope and the trachea was intubated with an appropriate endotracheal tube. Surgery began, maintenance of sedation using isoflurane, maintenance of analgesia with fentanyl according to the hemodynamic response, and maintenance of muscle relaxants using rocuronium. [isoflurane was used for sedation maintenace, fentanyl was used for analgesia maintenance according to the hemodynamic response, rocuronium was used for muscle relaxants maintenance.] pilih mau yg mana kalimatnya yg lebih pas menurut abg

After surgery was done and the patient fulfilled the extubation criteria, the patient was extubated and time was recorded as T0, and the VAS was assessed by showing the scale according to the pain perception felt by the patient. This assessment was carried out directly by researchers who were not involved in administering drugs to the patient.

The time the study began when group A received continuous intravenous oxycodone with an initial bolus of $5 \mathrm{cc}$ followed by $1 \mathrm{cc} /$ hour with a target VAS value $\leq 3$ for 24 hours, whereas group B received continuous intravenous morphine with an initial bolus of $4 \mathrm{mg}$ followed by 0.05 $\mathrm{mg} / \mathrm{kg} / \mathrm{hr}$ then the dose was increased to $1 \mathrm{cc} /$ hour with a target VAS value $\leq 3$ for 24 hours. The patient observed in the recovery room and transferred to the treatment room if the Aldrette Score is 10 . Equality assessment of drug dosages and side effects with a target vase value of $\leq 3$ is carried out directly by the researcher at 0 (T0), 1 (T1), 2 (T2), 3 (T3), 4 (T4), 6 (T5) ), 12 (T6) and 24 (T7) after the surgery is over.

The study was stopped if the study subjects refused to participate further, the operation was prolonged so that additional general anesthesia was needed, an allergic reaction to oxycodone or morphine occurred, and an emergency airway, heart, lung, and brain were threatened.

Results of observational data in the two groups were compared statistically. After the necessary data had been collected, then the data is checked again before tabulated and processed. Then the data is coded and tabulated into master tables using SPSS software. 


\section{Result}

The study was followed by 48 patients who had met the inclusion criteria, divided into two groups with the same number of lots, each totaling 24 people. Patients aged 19-29 years in the morphine group were 12 people (50\%), while in the oxycodone group were 7 people (29.2\%). Patients aged 30-39 years in the morphine group were 3 people (12.5\%), while in the oxycodone group were 2 people (8.3\%). Patients aged 40-49 years in the morphine group were 5 people (20.8\%), while in the oxycodone group were 6 people (25\%). Patients aged 50-59 years in the morphine group were 4 people (50\%), while in the group oxycodone as many as 9 people (37.5\%). Based on the age characteristics of the patients found relatively homogeneous data $(p>0.05)$.

Table 3.1. Distribution of Research Subjects by Age, Gender, and ASA

\section{Drugs}

Characteristic

Total $\mathbf{p}^{*}$ Value

Morphine Oxycodone

1. Age (tahun)

- $19-29 \quad 12(50 \%) \quad 7(29,2 \%) \quad 19(39,6 \%)$

- $30-39 \quad 3(12,5 \%) \quad 2(8,3 \%) \quad 5(10,4 \%)$

- $40-495(20,8 \%) \quad 6(25,0 \%) \quad 11(22,9 \%)$

- $50-59 \quad 4(16,7 \%) \quad 9(37,5 \%) \quad 13(27,1 \%)$

\begin{tabular}{llll}
\hline Total & $24(100 \%)$ & $24(100 \%)$ & $48(100 \%)$ \\
\hline
\end{tabular}

2. Gender

- Male $13(54,2 \%) \quad 15(62,5 \%) \quad 28(58,3 \%)$

\begin{tabular}{|c|c|c|c|c|}
\hline - Male & $13(54,2 \%)$ & $15(62,5 \%)$ & $28(58,3 \%)$ & 0558 \\
\hline - Female & $11(45,8 \%)$ & $9(37,5 \%)$ & $20(41,7 \%)$ & \\
\hline Total & $24(100 \%)$ & $24(100 \%)$ & $48(100 \%)$ & \\
\hline
\end{tabular}

3. ASA

- $\begin{array}{clll}\text { ASA } 1 & 11(45,8 \%) & 8(33,3 \%) & 19(39,6 \%)\end{array}$

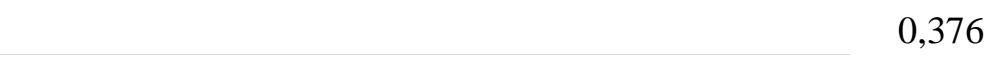

- $\begin{array}{cccc}\text { ASA } 2 & 13(54,2 \%) & 16(66,7 \%) & 29(60,4 \%)\end{array}$

Total

$24(100 \%) \quad 24(100 \%) \quad 48(100 \%)$ 
Based on the table, male subjects in the group that received morphine were 13 people $(54.2 \%)$ and in the group that received oxycodone there were 15 people $(62.5 \%)$. While female subjects who received morphine were 11 people $(45.8 \%)$ and in the group who received oxycodone there were 15 people $(62.5 \%)$. From the results of the table it can be concluded that the patients in this study were relatively homogeneous ( $p>0.05$ ).

Subjects with ASA 1 in the group that received morphine were 11 people (45.8\%) and in the group that received oxycodone there were 8 people (33.3\%). While ASA 2 subjects who received morphine were 13 people (54.2\%) and in the group who received oxycodone there were 16 people (66.7\%). From the results of the table it can be concluded that the patients in this study were relatively homogeneous $(\mathrm{p}>0.05)$.

Table 3.2. Distribution of Research Subjects based on preoperative VAS values

\begin{tabular}{|c|c|c|c|c|}
\hline \multirow{2}{*}{ Pre Op VAS } & \multicolumn{2}{|c|}{ Drug } & \multirow{2}{*}{ Total } & \multirow{2}{*}{$\mathbf{p}^{*}$ Value } \\
\hline & Morphine & Oxycodone & & \\
\hline 4 & $14(58,3 \%)$ & $11(45,8 \%)$ & $25(52,1 \%)$ & \\
\hline 5 & $10(41,7 \%)$ & $13(54,2 \%)$ & $23(47,9 \%)$ & 0,386 \\
\hline Total & $24(100,0 \%)$ & $24(100,0 \%)$ & $48(100,0 \%)$ & \\
\hline
\end{tabular}

*Chi-Square Tests

Figure 3.1. Distribution of Research Subjects based on preoperative VAS values

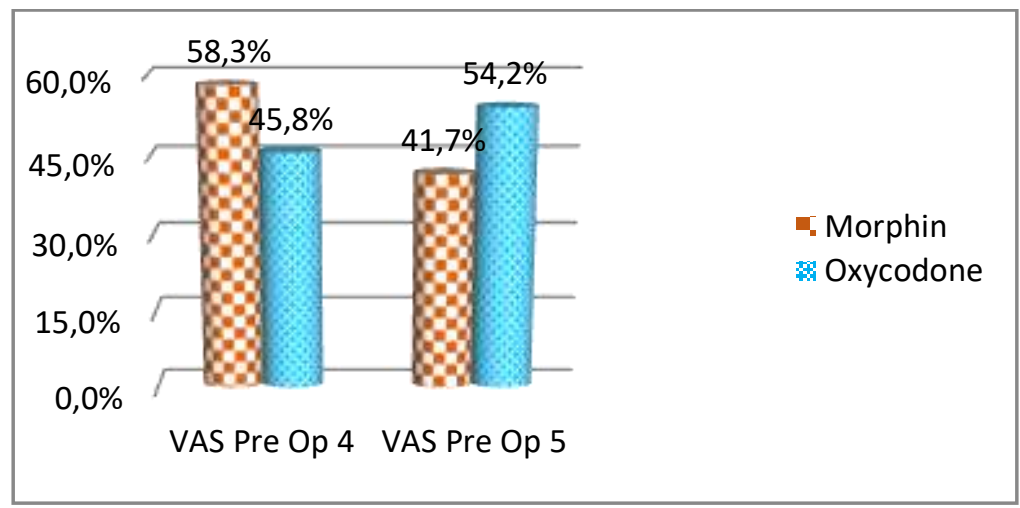

Based on the preoperative VAS table, subjects with preoperative VAS 4 in the group who received morphine were 14 people (58.3\%) and in the group who received oxycodone there were 11 people $(45.98 \%)$. While subjects with preoperative VAS score of 5 who received morphine were 10 people $(41.7 \%)$ and in the group who received oxycodone there were 13 people (54.2\%). From 
the results of the table it can be concluded that the patients in this study were relatively homogeneous ( $p>0.05)$.

Table 3.3. Difference in mean duration of surgery based on the drug given

\section{Duration of Surgery (Minutes)}

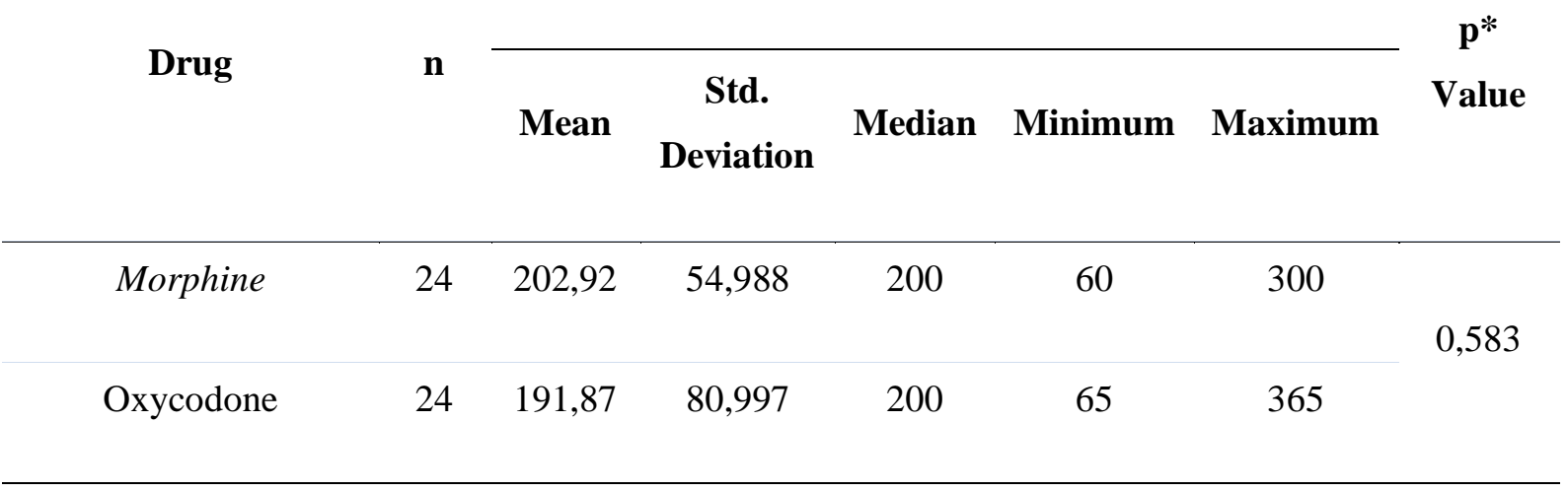

$$
* t-T e s t
$$

The mean duration of operation in the group given the Morphine drug was $202.92 \pm 54.99$ minutes a little longer than the average duration of operation in the group given the oxycodone drug was $191.87 \pm 80.10$ minutes. Statistical test with t-test showed no significant difference in operating time between the two groups of study subjects ( $p>0.05$ ).

Table 3.4. The difference in average time to reach VAS value of 3 based on the drugs given.

Time to reach VAS value of 3 (Hour)

\begin{tabular}{cccccccc} 
Drug & n & Mean & $\begin{array}{c}\text { Std. } \\
\text { Deviation }\end{array}$ & Median & Minimum & Maximum & \\
& & & & & & & \\
Morphine & 24 & 2,13 & 0,68 & 2 & 1 & 3 & \\
Oxycodone & 24 & 1,46 & 0,509 & 1 & 1 & 2 & \\
\hline
\end{tabular}

\section{*Mann-Whitney test}

The mean time to reach VAS $\leq 3$ in morphine group was $2.13 \pm 0.68$ hours, while the mean time to reach VAS $\leq 3$ in oxycodone group was $1.46 \pm 0.51$ hours. Mann-Whitney statistic test showed there were significant differences in time to achieve VAS $\leq 3$ between the two groups of study subjects $(\mathrm{p}<0.05)$. 
Table 3.5. Difference in mean dose of drug based on the drug given

\begin{tabular}{|c|c|c|c|c|c|c|c|}
\hline \multirow{2}{*}{ Drug } & \multirow{2}{*}{$\mathbf{n}$} & \multicolumn{5}{|c|}{ Dose (mg) } & \multirow{2}{*}{$\begin{array}{c}\mathbf{p}^{*} \\
\text { Value }\end{array}$} \\
\hline & & Mean & $\begin{array}{c}\text { Std. } \\
\text { Deviation }\end{array}$ & Median & Minimum & Maximum & \\
\hline \multirow[t]{2}{*}{ Morphine } & 24 & 3,9021 & 0,45956 & 4 & 3 & 5 & \\
\hline & & & & & & & 0,001 \\
\hline Oxycodone & 24 & 1,4583 & 0,50898 & 1 & 1 & 2 & \\
\hline
\end{tabular}

*Mann-Whitney test

The mean dose of morphine group was $3.90 \pm 0.46 \mathrm{mg}$, while the mean dose of oxycodone group was only $1.46 \pm 0.51 \mathrm{mg}$. Statistical tests with the Mann-Whitney test showed there were significant differences in the mean drug dose between the two groups of study subjects $(p<0.05)$.

From the statistical test results, the dose range of oxycodone to reach VAS $\leq 3$ is $1-2 \mathrm{mg}$, with an average time of 1.46 hours. Morphine dose range to reach VAS $\leq 3$ is $3-5 \mathrm{mg}$ with an average time of 2.13 hours. The average body weight of the patient was $62.5 \mathrm{~kg}$, so it was obtained about the average dose of oxycodone is 0.02 to $0.04 \mathrm{mg} / \mathrm{kgBW} /$ hour and the range dose of morphine is $0.02 \mathrm{~s} / 0.03 \mathrm{mg} / \mathrm{kgBW} / \mathrm{hour}$.

\section{Discussion}

This study assessed the equianalgesic doses of oxycodone and morphine in pain management of post-long bones surgery. Research and guidelines for pre-dose equation are limited to single dose and opioid rotation, and no similar studies have been conducted in Indonesia or Asia.

Inadequate pain management will cause Metabolic Stress Response (MSR) which will affect all body systems and aggravate the patient's condition. This will harm the patient due to physiological and psychological changes such as cognitive (central) changes, neurohumoral changes, neural plasticity sympathoadrenal activation, and neuroendocrine changes (Sommer, 2008), (Morgan, 2013).

Pain if not treated properly will result in chronic pain. Jane in 2008 explained that chronic pain can be in the form of hyperalgesia and allodynia which treatment for this type of pain is very difficult so that treatment for acute pain must be as good as possible to prevent the onset of chronic pain. This study is devoted to the management of post-surgical pain which is a problem for 
patients because after the effects of anesthetic drugs are gone, sufferers will feel pain. The use of adequate post-surgical analgesic drugs is important so that chronic pain and emotional disturbances do not occur. Quality pain management has a role to help speed up the healing process.

This study was followed by 48 samples that met the inclusion criteria. The sample was divided into two groups. Group 1: 24 samples that received intravenous morphine with an initial bolus of $4 \mathrm{mg}$ continued with a dose of $0.05 \mathrm{mg} / \mathrm{kgBB} /$ hour continuously with an increase in dose of $0.5 \mathrm{mg} /$ hour until VAS $\leq 3$ was reached. Group 2: from 24 samples who received intravenous oxycodone with an initial bolus of $5 \mathrm{mg}$ followed by a continuous $1 \mathrm{mg} /$ hour dose with $1 \mathrm{mg} / \mathrm{h}$ dose increase until VAS $\leq 3$ was reached.

From the characteristics of the sample data it can be seen that the age between the two groups of samples there is no statistically significant difference, thus the sample taken is relatively homogeneous ( $p>0.05$ ). Similarly, the gender, ASA physical status, VAS Pre op and duration of operation between the two sample groups were not statistically significant ( $p>0.05)$. Based on the age characteristics of the patients found relatively homogeneous data. $(p>0.05)$

Statistical test results of the average time difference to reach VAS $\leq 3$ based on the drug given was found that the average time in the morphine group was $2.13 \pm 0.68$ hours longer than the average time in the oxycodone group with $1.46 \pm 0.51$ hours. The results of the Mann Whitney Test statistic showed that there were significant differences between the two groups $(p<0.05)$.

Based on statistical tests on the average dose used to achieve VAS $\leq 3$, it was found that the average dose of the group of drugs given morphine was $3.90 \pm 0.46 \mathrm{mg}$ more than the group given oxycodone as much as $1.46 \pm 0.51 \mathrm{mg}$. Statistical tests with the MANN Whitney Test showed significant differences between the two groups $(\mathrm{p}<0.05)$.

Based on the theory presented by Kalso (2007), pharmacologically oxycodone is a $\mu$-receptor agonist, but has a lower affinity than morphine. Oxycodone itself also binds to opiate $\kappa$ and $\sigma$ receptors, while morphine predominantly binds to $\mu$ opiate receptors. The $\mu$ and $\sigma$ receptors are known to play a role in the analgesic effect of opiates, while the role of the $\kappa$ receptor is also meaningful but it still requires further in vitro research. This oxycodone bond to the $\mu, \kappa$ and $\sigma$ opiate receptors which mediates the analgesic effect of oxycodone so that it is effective in relieving postoperative pain. This might result in a significant difference from the average dose used to achieve VAS $\leq 3$, where oxycodone has a lower average dose than morphine. 
The results of the Mann Whitney Test statistic on the average dose used to achieve VAS $\leq 3$ also showed that the mean (mean) dose used in the morphine group was $3.9021 \mathrm{mg}$ while in the oxycodone group was $1.4583 \mathrm{mg}$. The pharmacology of oxycodone acting on the $\mu, \kappa$ and $\sigma$ receptors, albumin bonds are higher than morphine, and differences in metabolic processes may be the cause of the average use of oxycodone doses lower than morphine.

Eastern Metropolitan in 2010 explained that the administration of morphine $10 \mathrm{mg}$ parenterally has the same effect as oxycodone $10 \mathrm{mg}$. Research conducted by Choi in 2016 explained that the equivalent dose between oxycodone and morphin is equal to $10 \mathrm{mg}$. Byung in 2016 examined the potential ratio of morphine and oxycodone, which found an equivalent morphine and oxycodone intravenously is 1: 1 . Another study conducted by Kalso (1991) of 109 research subjects comparing oxycodone and intravenous morphine as analgesic drugs after laparoscopic hysterectomy surgery with the potential comparison results between oxycodone and intravenous morphine with PCA was 2: 3.

The difference in the results of this study is due to differences in the treatment of oxycodone and morphine, namely in this study continuous infusion was used, whereas in other studies using only a single bolus injection of oxycodone or morphine drugs. In addition, in this study, the purpose of using this analgesic drug was to achieve a VAS value of $\leq 3$ whereas in other studies only assessed the effectiveness of oxycodone as a substitute for opiate analgesic drugs that are often used. In the Kalso (1991) study no VAS was assessed so the subjectivity of this study was high.

The results of this study are equalization of continuous intravenous infusion doses between the two drugs. This study did not assess the occurrence of side effects that occurred from the two drugs. Increasing the dose of opiate medications increases the risk for side effects from opiates. Future studies using opiates should assess the side effects that occur in accordance with the dose given.

\section{Conclusion}

From the results of this research that have been carried out on the value of VAS in measuring the equivalent dose (equianalgesic doses) in patients after long bone surgery by comparing the administration of oxycodone and morphine can be concluded:

1. There is an equivalent dose (equianalgesic doses) in the oxycodone and morphine groups. Continuous intravenous infusion of $1.4 \mathrm{mg}$ of oxycodone and $3.9 \mathrm{mg}$ of morphine is effective in dealing with pain after long bone surgery.

2. The time needed to achieve a $\leq 3$ VAS value after long bone surgery was shorter in the oxycodone group (mean 1.46 hours) compared to the morphine group (average 2.13 hours). 


\section{Suggestion}

1. Administration of intravenous bolus of $5 \mathrm{mg}$ oxycodone followed by $0.02-0.04 \mathrm{mg} /$ $\mathrm{kg} / \mathrm{hr}$ continuous infusion of oxycodone can be used to treat pain following long bone surgery.

2. Further research is needed regarding the use of intravenous bolus of $5 \mathrm{mg}$ oxycodone followed by $0.02-0.04 \mathrm{mg} / \mathrm{kg} / \mathrm{hr}$ continuous infusion of oxycodone in various types of operations.

3. Further research is needed to be done on the equivalence of dosages and side effects that can occur in the use of this drug.

\section{REFERENCES}

[1] Morgan GE, Mikhail MS, Murray MJ. Perioperative pain managament \&enhanched outcomes. In: Clinical anesthesiology, $5^{\text {th }}$ ed. Lange Medical Books/McGraw-Hill, 2013: 1087-105.

[2] Rawal N, Fischer HBJ, Ivani G, et al. Postoperative pain management - good clinical practice. European Society of Regional Anestesi. Sweden, 2008.

[3] Stoelting RK, Hillier SC. Pain. In: Pharmacology \&physiology in anesthetic practice, $4^{\text {th }}$ ed. Lippincott Williams \& Wilkins, 2006: 707-17.

[4] Misiolek H, Cettler M, Woron J, et al. The 2014 Guidelines For Post-Operative Pain Management. 2014.

[5] Plante GE, VanItallie TB. Metabolism Clinical and Experimental . 2010: 59 (Suppl 1): S47-S52

[6] OxyNorm ${ }^{\circledR}$ solution for injection or infusion $10 \mathrm{mg} / \mathrm{mL}$ PI. Mundipharma Pty Ltd, Sydney, NSW. 23 Dec 2015.

[7] Silvasti M, Tarkkila P, Tuominen M et al (1999) Efficacy and side effects of tramadol versus oxycodone for patient-controlled analgesia after maxillofacial surgery. Eur J Anaesthesiol 16(12): 834-9.

[8] Lenz Harald, Sandvik Leiv, Qvigstad Erik, dkk. A Comparison of Intravenous Oxycodone and Intravenous Morphine in Patient-Controlled Postoperative Analgesia After Laparoscopic Hysterectomy. International Anesthesia Research Society. 2009: 109(4): 1279-1283

[9] Sommer M, de Rijke JM, van Kleef M, Kessels AG, Peters ML, GeurtsJW et al. The prevalence of postoperative pain in a sample of 1490 surgical inpatient. Eur J Anaesthesiol, 2008; 25: 267-74 
[10] Jane, C. Ballantyne.,2008. Acute Pain Management. In: Longnecker D, Brwon D, Newman M, Zapol W. Anesthesiology. USA. The McGraw-Hill Companies. pp. 1743-63.

[11] Kalso E, Sarella MV, et all. The Compassionate Brain : human detect of pain from another's face. Cereb Cortex. 2007 Jan; 17(1): 230-7.

[12] Eastern Metropolitan Regio Palliative Care Consortium. Opioid Conversion Ratios : Guideline to Practice. Melbourne. 2010, www.emrpcc.org.au/wpcontent/uploads/2013/03/EMRPCC-Opioid-Conversion2010-Final2.pdf (Accessed: February, 2017) 